\title{
Neutral Beam Development Plan
}

U.S. Department of Energy

Office of Energy Research

Office of Fusion Energy

Division of Development and Technology

August 1980
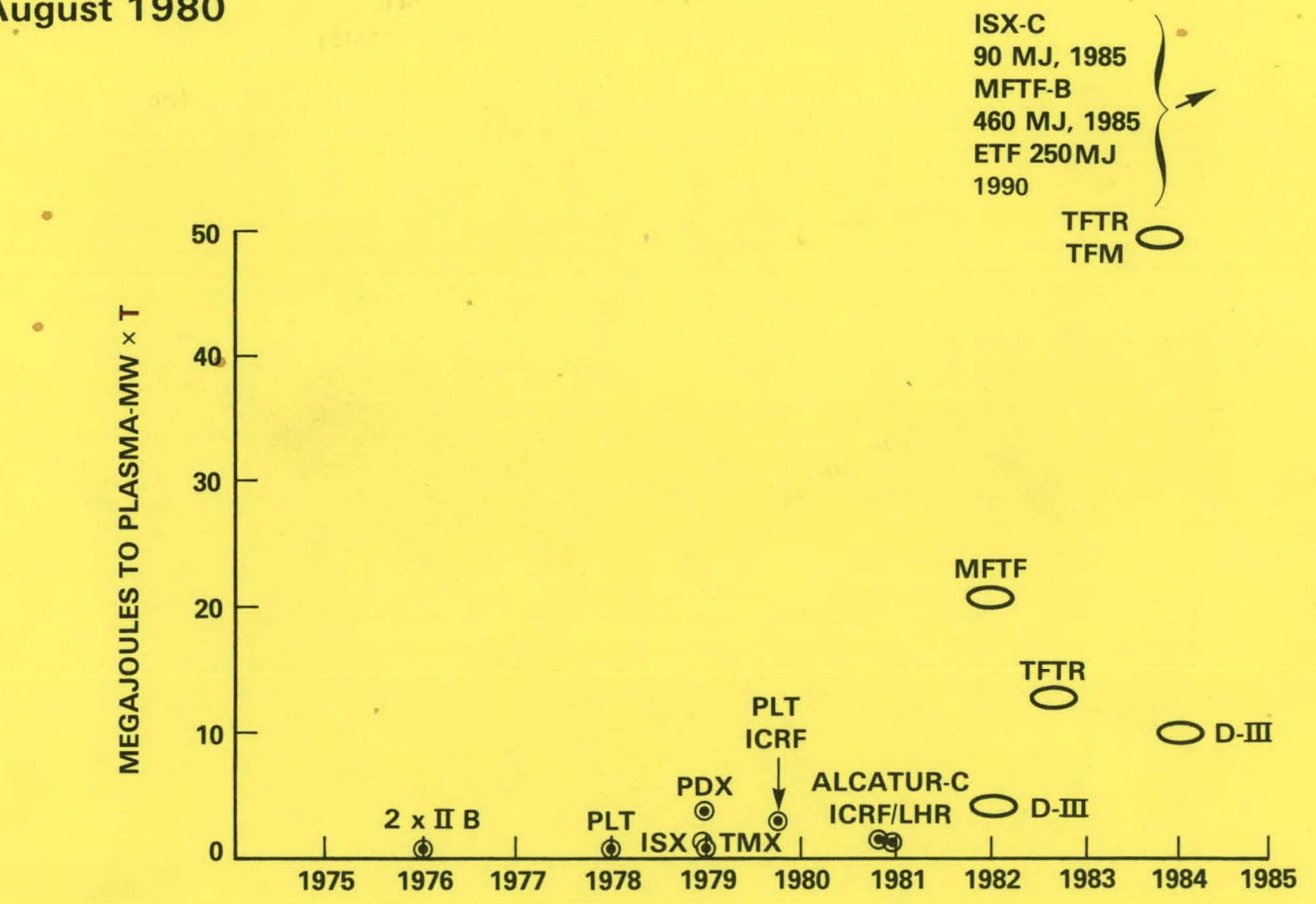


\section{DISCLAIMER}

This report was prepared as an account of work sponsored by an agency of the United States Government. Neither the United States Government nor any agency Thereof, nor any of their employees, makes any warranty, express or implied, or assumes any legal liability or responsibility for the accuracy, completeness, or usefulness of any information, apparatus, product, or process disclosed, or represents that its use would not infringe privately owned rights. Reference herein to any specific commercial product, process, or service by trade name, trademark, manufacturer, or otherwise does not necessarily constitute or imply its endorsement, recommendation, or favoring by the United States Government or any agency thereof. The views and opinions of authors expressed herein do not necessarily state or reflect those of the United States Government or any agency thereof. 


\section{DISCLAIMER}

Portions of this document may be illegible in electronic image products. Images are produced from the best available original document. 
Printed in the United States of America Available from

National Technical Information Service U.S. Department of Commerce 5285 Port Royal Road Springfield, VA 22161

NTIS price codes

Printed Copy: $\quad \$ 4.50$

Microfiche Copy: $\$ 3.50$ 


\section{Neutral Beam Development Plan}

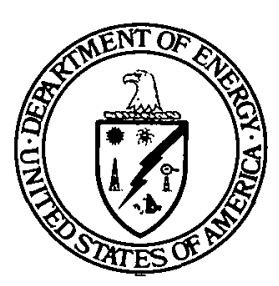

\section{U.S. Department of Energy}

Office of Energy Research

Office of Fusion Energy

Division of Development and Technology

Washington, D.C. 20545

\section{August 1980}

Compiled by

H. Stanley Staten, OFE/DOE
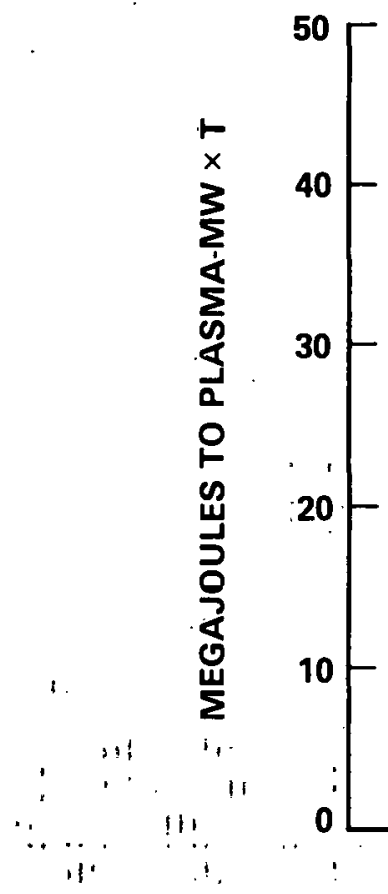

DOE

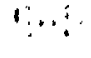

ISX-C

$90 \mathrm{MJ}, 1985$

MFTF-B

$460 \mathrm{MJ} ; 1985$

ETF 250.MJ

1990

TFTR

TFM

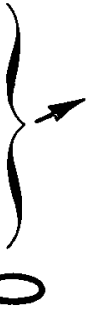

D-III

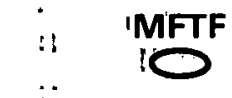

LT

ICRF

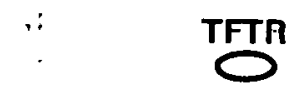

ALCATUR-C

$O$ ICRF/LHR $\longrightarrow$ D-III

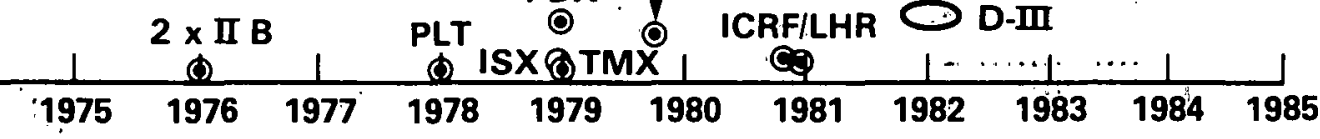

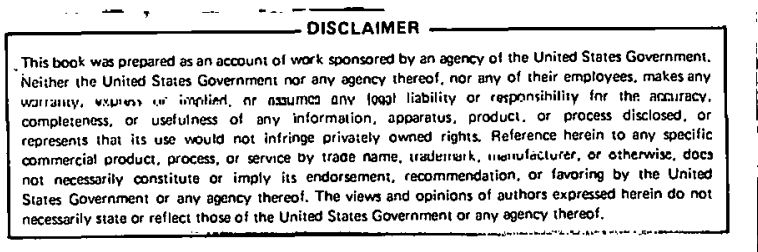

FIGURE I-1

GISTABBUTIOH OF THIS OOCUMEIT IS UHLIFATER 
This Neutral Beam Development Plan delineates the development program of the Development and Technology Program of the Office of Fusion Energy. It responds to the user needs as best we can define them and within the budget constraints imposed by other programmatic considerations.

The Magnetic Fusion Energy Program is a dynamic program. It is progressing rapidly as physics understanding improves and the need to develop the engineering aspects becomes more apparent. As such, the neutral beam development program must adapt and change as program priorities dictate. The program plan should, therefore, be considered as a snapshot in time, representing only our present understanding of the activities that will be required.

This plan is the culmination of efforts extending over almost three years, starting with the Plasma Heating Requirements Workshop, CONF-771241, December 1977. Several user/developer workshops have been held and finally a program review including a review of the draft program was held in March 1980.

Many people have been involved in these efforts, but particular thanks is extended to Larry Stewart, Hal Haselton, Bob Pyle, Bob Borchers, Krsto Prelec, and Theo sluyters for their efforts and patience in bringing this effort to fruition.

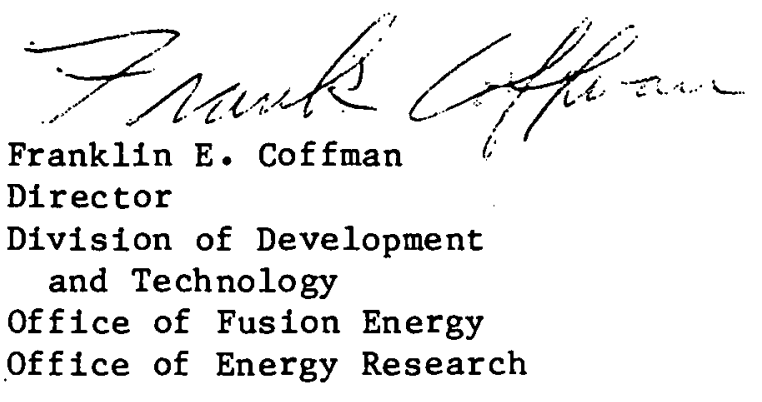


Table of Contents

$\underline{\text { Page (s) }}$

I. Introduction $\ldots \ldots \ldots \ldots \ldots \ldots \ldots \ldots \ldots \ldots \ldots \ldots \ldots \ldots \ldots \ldots \ldots \ldots 1-3$

II. Neutral Beam System Requirements.................... 9

A. Current Projects

B. Upgrades of Current Projects

C. Future Projects

1. Tokamaks

2. Mirror Systems

3. Alternate Concepts

D. Reliability

E. Value Engineering and Cost Reduction

F. Technology Transfer to Industry

III. Neutra1 Beam Technology -- State-of-the-Art............9-12

A. Positive Ion Systems

B. Negative Inn Systems

IV. Program Plan..................................
A. Needs Summary
B. Strategy
i. Positive Ion Systems
2. Negative Ion Systems
C. Test Facilities
1. LBL
2. ORNL
D. Detail Program Plan
1. Positive Ion Systems
2. Negative Ion Systems
E. Budgets

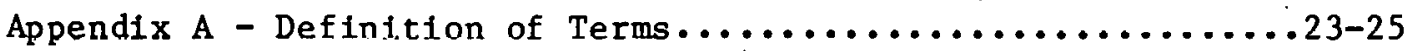

B - Glossary of Abbreviations................. 26 
The only method proven to date to be capable of heating plasmas to reactor like conditions is injection of a high energy neutral beam of atoms. Plasma ion temperatures exceeding $7 \mathrm{KeV}$ have been attained in PLT and $13 \mathrm{KeV}$ In 2 XIIB by use of neutral beam injection. Neutral beam injection experiments are in progress or are being" built for ISX, TMX, PDX, Doublet-III, MFTF, and TFTR. The neutral beam systems for TFTR are planned to drive the plasma to conditions where net energy production will result:

The national plan is presented for developing even more advanced injection systems for use on upgrades of existing experiments, and use on future facilitles such as ETF, to be built in the late $1980^{\circ} \mathrm{s}$ or early $90^{\circ} \mathrm{s}$ where power production from magnetic fusion will move closer to a reality. Not only must higher power and longer pulse length systems be developed, but they must operate rellably; they must be a tool for the experimenter, not the cxpcriment itoclf. Neutral boam eyetome handle lárge amounts of energy and as such, they often are as complicated as the plasma physics experiment itself. This presents a significant challenge to the neutral beam developer.

The need for aggressive development must be balanced against the funding available. This program plan is based upon essentially a level budget. This presents significant constraints upon the activities than can be pursued. However, the early development needs of the program as outlined herein can be met. 


\section{Introduction}

The only proven method of heating modern state-of-the-art magnetically confined plasmas to reactor-like conditions is by intense injection of high energy neutral beams. The recent record plasma temperatures of $7 \mathrm{KeV}$ attained in PLT and the $13 \mathrm{KeV}$ in $2 \mathrm{XIIB}$ are graphic demonstrations of the success of high power neutral beam injection heating. The PLT neutral beam heating experiment is only the first of a succession of planned plasma physics and engineering experiments which are expected to lead to demonstration of economical fusion power as a viable option in the energy future of the world.

Figure I-1 shows some of the past and the near term future ( 10 years) expected heating energy needs. Note that while PLT produced significant results, the total energy delivered to the piasma was small ( $<1 / 2$ Mega Joule) compared to the very near term PDX ( 23 Mega Joule), Doublet-III ( 10 Mega Joule), ISX-C ( 90 Mega Joule), MFTF-B ( 460 Mega Joule), and the TFTR TFM ( $\sim 50$ Mega Joule). The projected need for the Tokamak Engineering Test Facility (ETF) is $\sim 250$ Mega Joule. Even with the success that has been attained with neutral beam injection, the future needs require very aggressive development.

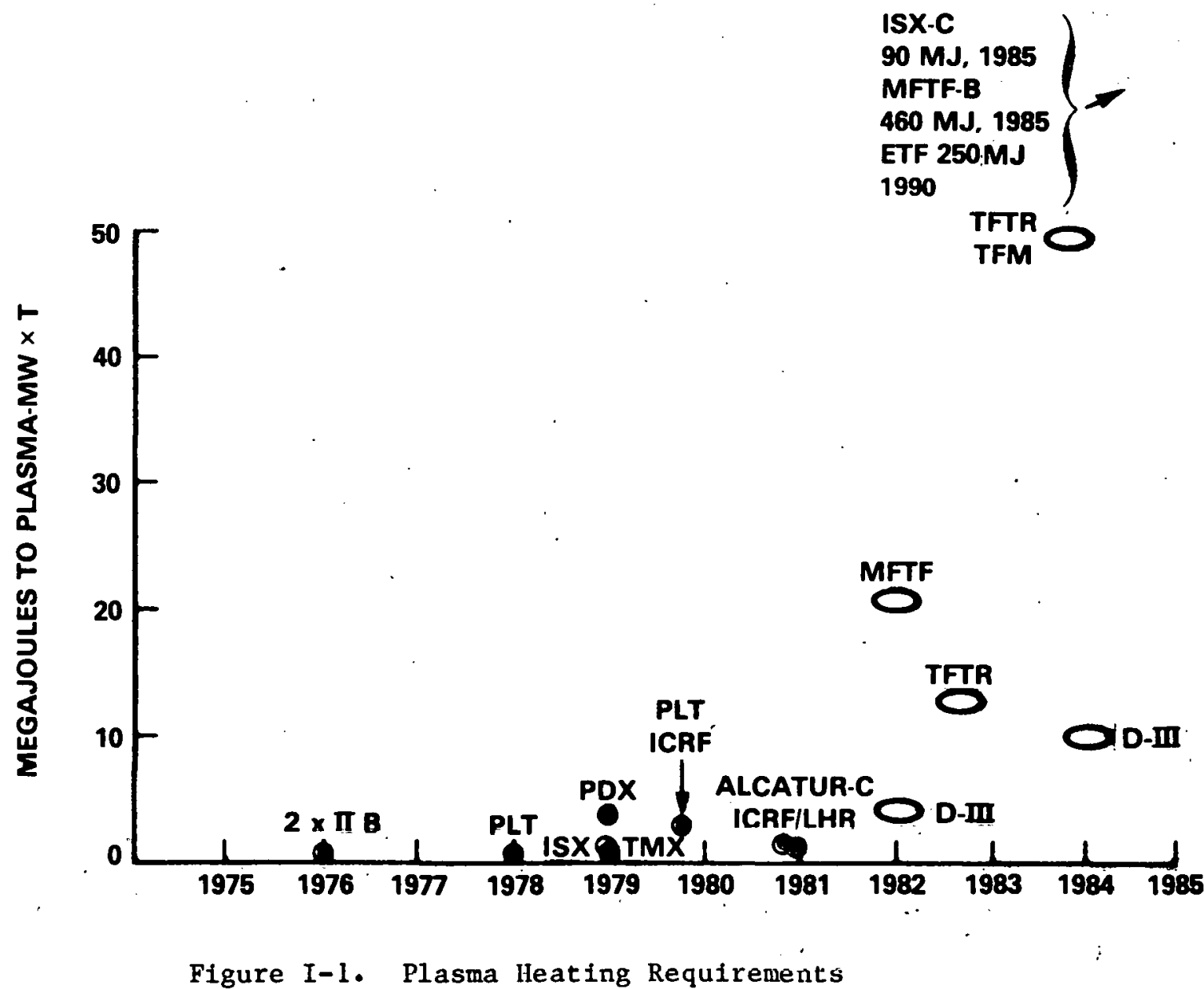


There has been much analysis, discussion, and interaction within the Magnetic Fusion Energy community over the last several years concerning requirements and directions the neutral beam development program should take to meet the needs of an evolving magnetic fusion energy development program. The Magnetic Fusion Energy Program Plan is being developed by the DOE's Office of Fusion Energy. It is based on the sets of plans or planning "paces" designated"as Paces A, B, and C; each one differing in funding profiles and milestone dates. The schedule and arrangement of the principle facilities for the three paces are shown in Figure I-2. Central

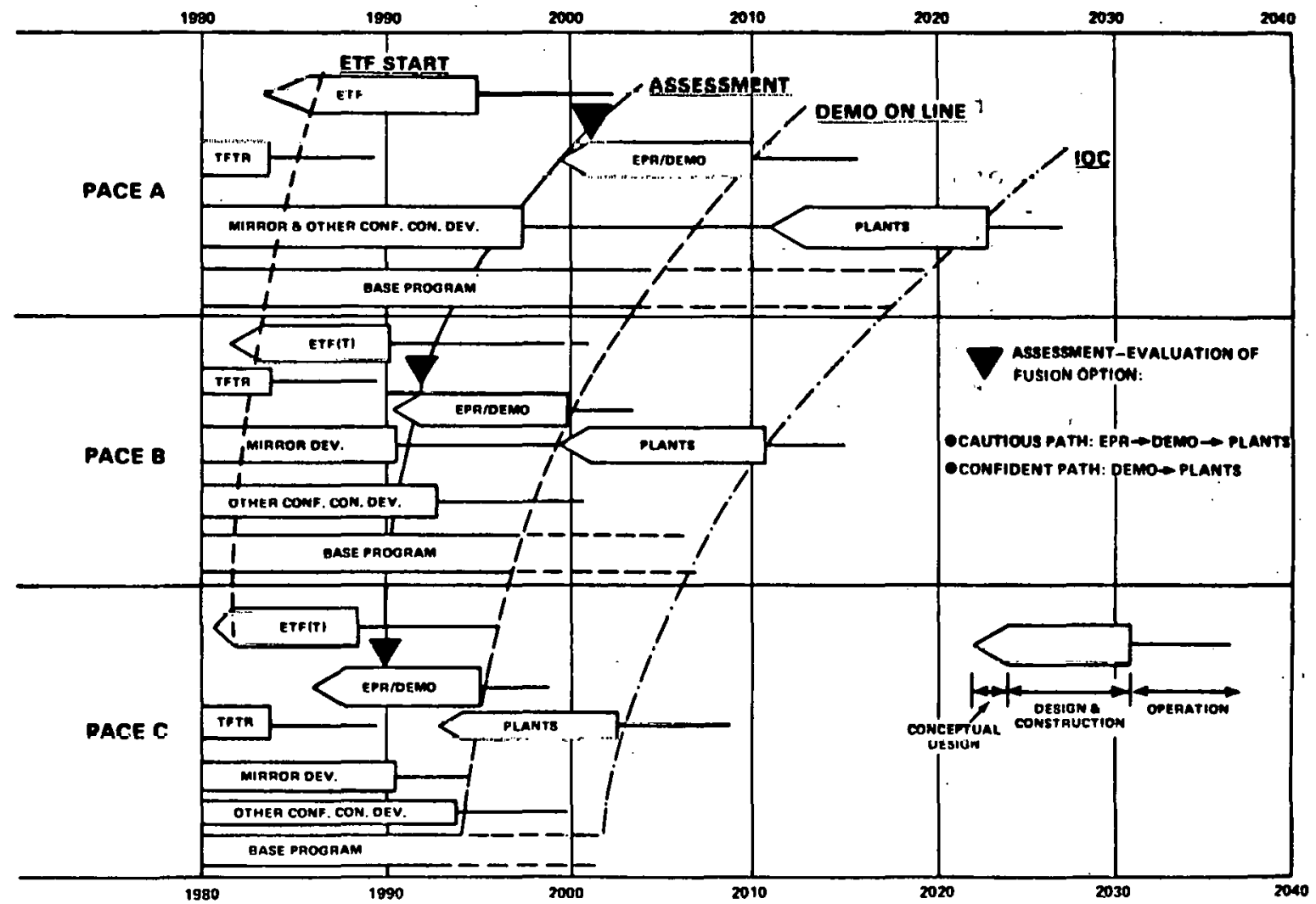

Fig. I-2. Details of the major facilities and decision points of the three program paces laid out in the National Magnetic Fusion Program Plan

to the Magnetic Fusion Energy Program Plan is the decision to construct an Engineering Test Facility (ETF) that will have as its purpose, the demonstration of the technology and engineering feasibility of fusion energy. This Neutral Beam Development Program Plan addresses Pace A of the Magnetic Fusion Energy Program Plan.

There now appears to be reasonable agreement in the United States on the minimum future tokamak needs. Extensions of existing positive ion based systems can satisfy these needs. Mirror requirements may be 
somewhat more stringent, but have much in common with tokamaks for present generation mirror experiments. Longer term'mirror systems needs and possibly. longer term tokamak needs, however, are for neutral beam energies that are higher than can be provided using positive ion based systems; hence, the need to develop negative ion based systems. The purpose of this plan is to lay out a strategy and logic that, if pursued, will provide a reasonable degree of confidence in meeting the requirements for plasma heating inherent in the office of Fusion Energy planning paces. The specific neutral beam heating requirements are discussed in the remainder of this plan.

II. Néutral Beam Systems Requirements

ᄀ

A. Current Projects

The neutral beam systems for current plasma experiments are listed in Table II-1. This table lists the basic system requirements. There are significant upgrades under discussion or active consideration that will be discussed in the next section.

\begin{tabular}{|c|c|c|c|c|c|}
\hline & $\begin{array}{l}\text { Energy } \\
(\mathrm{KeV}) \\
\end{array}$ & $\begin{array}{l}\text { Current } \\
\text { Per Source } \\
\text { (Amperes) }\end{array}$ & $\begin{array}{l}\text { Pulse Length } \\
\text { (Milli Secs) }\end{array}$ & $\begin{array}{c}\text { Species } \\
\text { (\% Full Energy) } \\
\end{array}$ & $\begin{array}{c}\text { Operating } \\
\text { Gas }\end{array}$ \\
\hline PLT & 40 & 60 & 300 & $85 \%$ & $H, D$ \\
\hline ISX-B & 40 & 100 & 100 & $85 \%$ & $\mathrm{H}, \mathrm{D}$ \\
\hline \multirow[t]{2}{*}{ TMX } & 40 & 40 & 25 & $65 \%$ & D \\
\hline & 20 & 50 & 25 & $65 \%$ & $\mathrm{D}, \mathrm{H}, \mathrm{He}$ \\
\hline PDX & $50^{\circ}$ & 100 & 500 & $85 \%$ & H,D \\
\hline TFTR & -120 & 65 & 500 & $85 \%$ & $\mathrm{H}, \mathrm{D}$ \\
\hline Doublet-I II & 80 & 80 & 500 & $60 \%$ & $\mathrm{H}$ only \\
\hline \multirow[t]{2}{*}{ MFTF } & 80 & 80 & 500 & $65 \%$ & D \\
\hline & 20 & 100 & 100 & $65 \%$ & $\mathrm{D}$ \\
\hline
\end{tabular}

Table II-1. Requirements for Current Projects

The neutral beam system tor PLT was developed by the Oak Ridge National Laboratory (ORNL). The neutral beam injector for ISX and PDX are based on the PLT systems. ISX has been using the PLT source. As a system upgrade, $100 \mathrm{~A}$ source has been installed on ISX. The PDX system will also use a 100 A source, upgraded to $50 \mathrm{KeV}$ operation at a longer pulse length. The PDX and ISX beamlines are upgraded PLT systems with an additional cryogenic vacuum pump.

The neutral beam injectors for TFTR, MFTF, and Doublet-III are based on the Lawrence Berkeley Laboratory (LBL) $10 \mathrm{~cm} \times 40 \mathrm{~cm}$ source that has been used successfully on 2 XII-B and TMX. By using very similar sources for these 3 projects, development costs can be reduced while reliability, and maintainability can be enhanced. 
B. Upgrades of Current Projects

Both theory and experiment show that improved plasma performance can be achieved by increasing some or all of the injector parameters, including injected particle energy (operating voltage), current, pulse length, and full-energy-fraction. Upgrades currently in progress or in the planning phases are listed in Table II-2. The parameters listed in Table II-2 are the best estimate of the requirements at the time of publication of this document. They are subject to change as the specific applications are firmed up.

\begin{tabular}{|c|c|c|c|c|c|}
\hline Project & $\begin{array}{l}\text { Energy } \\
\text { (KeV) } \\
\end{array}$ & $\begin{array}{l}\text { Current } \\
\text { (Amperes) }\end{array}$ & $\begin{array}{l}\text { Pulse Length } \\
\text { (Seconds) } \\
\end{array}$ & $\begin{array}{c}\text { Operating } \\
\text { Gas } \\
\end{array}$ & $\begin{array}{c}\text { Need } \\
\text { Date } \\
\text { Experiment } \\
\end{array}$ \\
\hline TFTR/T FM & 120 & 65 & $11 / 2$ & D & 1983 \\
\hline ISX-C & 50 & 100 & 30 & $\mathrm{H}$ & 1984 \\
\hline MFTF-B & 80 & 50 & 30 & D & 1985 \\
\hline Doublet-III & 80 & 80 & $\leq 5-10$ & $\mathrm{H}$ & 1986 \\
\hline
\end{tabular}

Table II-2. Neutral Beam Kequirements for Facility

Upgrades and Future Projects

\section{Future Projects}

1. Tokamaks.

The major problem anticipated with neutral beam heating of large tokamaks is the need for long pulse lengths and the lack of beam penetration. The first response to the penetration problem has been to raise the injection energy, but this entails severe penalties in injection efficiency. As the accelerated positive deuterium ion energy is increased beyond about $200 \mathrm{KeV}$, the efficiency of neutralizing the fast positively charged ions decreases to below 20 percent. (See Figure II-3) This low efficiency would necessitate a very large investment in sources, power supplies, pumps, and other hardware. Above $775 \mathrm{KeV} /$ nucleon*, negative ion injector systems which have a much higher neutralization efficiency appear attractive; however, such an injector has yet to be developed.

Early tokamak reactor designs such as UWMAK I were based on ronservative pl.asma physics expectations and employed very high energy neutral beam injectors $(500-1000 \mathrm{KeV})$ to penetrate to the

*Energy per nucleon is the key parameter. For $150 \mathrm{KeV}$ deuterium, the energy per neucleon is $75 \mathrm{KeV}$. Neutralization efficiency is a function of velocity or energy per neucleon rather than total energy. 


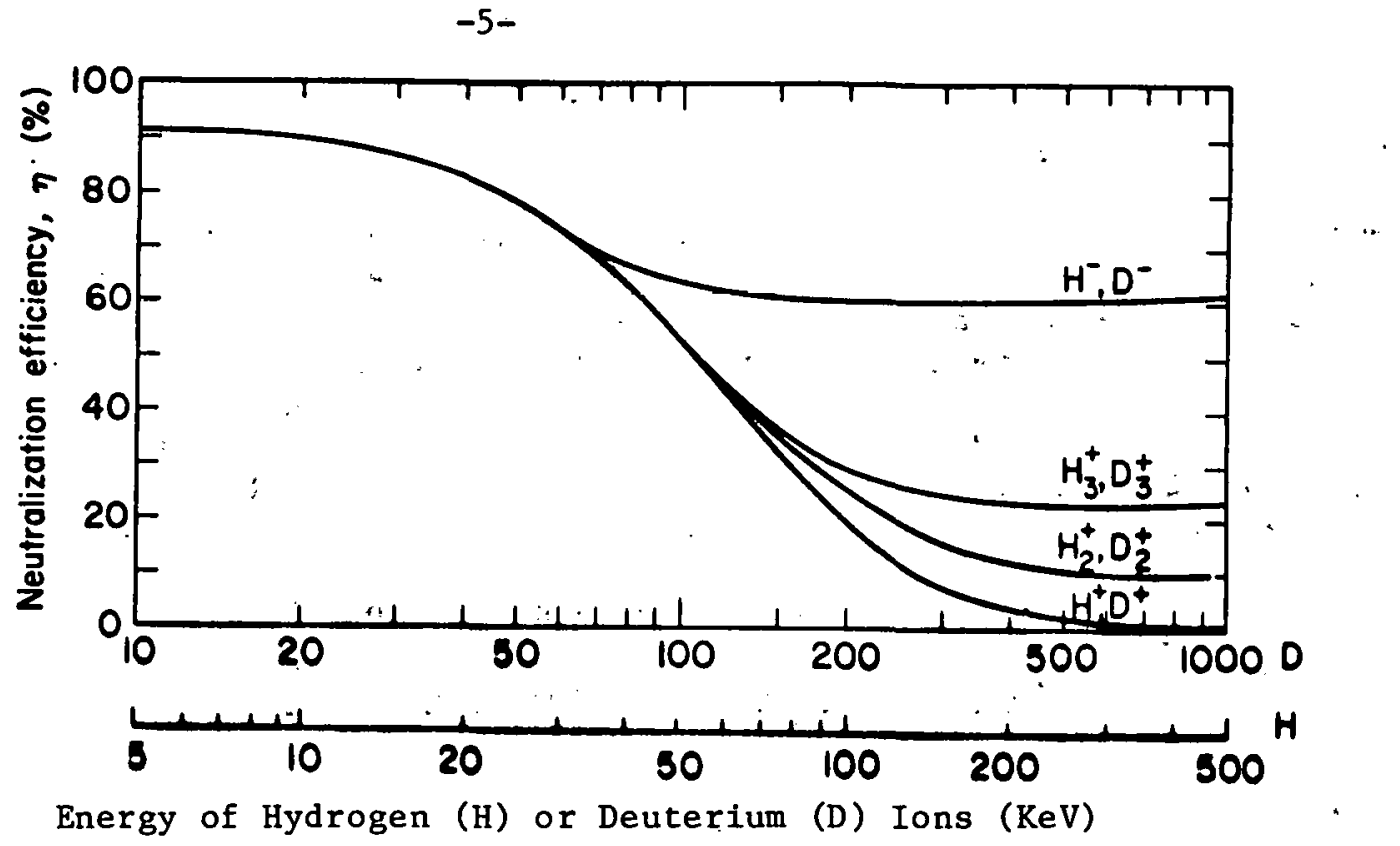

Figure II-3. Neutralization Efficiency Versus Energy

center of a very large plasma. As plasma physics understanding increased and the size of the various reactor designs decreased, the neutral beam energy requirements also decreased. From this work has emerged the conclusion that positive ion neutral beam injectors of $\sim 150 \mathrm{KeV}$ should be adequate for ETF size devices. These analyses recognize that the high density, high $B$ characteristics of an ignited plasma do not exist at initial startup. The initial plasma is a lower density cooler plasma, possibly also of smaller size where beams of $\sim 150 \mathrm{KeV}$ can penetrate to or nearly to the center. As the plasma builds up to its full operating parameters, the beam penetration is reduced; however, heating of the plasma core begins to be provided by the confined, energetic alpha particles generated by $D-T$ reactions. This makes a non-DT experiment more difficult from a neutral beam perspective in that alpha particles are not generated and higher energy neutral beams are required to provide heating of the plasma center.

The power required to heat plasmas to ignition is not known defintively. Analysis shows that for ETF and INTOR type devices, injected beam power requirements are in the range of 40 to $75 \mathrm{MW}$. It seems advisable to specify a heating capacity at the upper end of this range, as any margin in this specification provides increased reliability through installed redundancy or less stringent operating conditions.

Depending on transport scaling and on the heating scenario adopted, a heating pulse length of 3 to $8 \mathrm{~s}$ is required for ETF and INTOR. type devices. 
Various operational scenarios and testing plans call for driving a plasma almost to ignition and then maintaining this sub-ignition state by making up losses with neutral beam injection. The neutral beam injector systems must, therefore, be capable of operation for the full machine pulse length. This may be the most demanding operating mode.

In summary, the Neutral Beam requirements for ETF and INTOR type devices are:

$$
\begin{array}{ll}
\text { POWER } & 40-75 \mathrm{MW} \\
\text { ENERGY } & 120-200 \mathrm{KeV}(1.50 \mathrm{KeV} \text { nomina1.) } \\
\text { PULSE LENGTH } & 10 \mathrm{sec} \text { to the device pulse length }
\end{array}
$$

These neutral beam parameters also appear to be typical of the requirements of a Tokamak Demonstration Reactor.

\section{Mirror Systems}

Neutral beam injection is the only demonstrated method for maintalning a magnetic mirror plasma. The mirror program is aggressively pursuing the tandem mirror approach where magnetic mirror cells are used to plug the ends of a central solenoid.

The neutral beam energy required to drive a simple tandem mirror reactor ranges from $150 \mathrm{KeV}$ to $400 \mathrm{KeV}$.

The basic ideas of the tandem mirror have been tested on TMX and TMX upgrade. The results are very encouraging and in agreement with predictions. The next major proposed step after TMX is MFTF-B. MFTF is presently being built as a large single cell mirror. Lawrence Livermore Laboratory has proposed to use MFTF as one end plug of a large tandem mirror (MFTF-B). A duplicate MFTF magnet would be constructed and used as the other end plug. A 25 meter long solenoid would connect the plugs. With a thermal barrier, this device is expected to give a DT equivalent energy gain of one or break even. Neutral beams of $80 \mathrm{KeV}$, ( 30 second), will be used to heat the central cell and end plugs. Use of $80 \mathrm{KeV}$ negative ion neutral beams are being considered for pump beam application on MFrF-B because negative ton systems do not produce half and third energy components.

The Tandem Mirror Next Step is the first DT burning mirror equipment. For planning purposes it is assumed that the design will be fixed by 1986 and construction will begin in 1990. Scenarios 
exist in which the maximum injection energy is in the $150-200 \mathrm{KeV}$ range. However, optimization of the overall system could possibly require the injection energy to be even higher. In any event, it appears at the present time that both physics and radiationeffects considerations may lead to a choice of neutral hydrogen (rather than deuterium) for the high-energy end cell neutral. beams. This would force the neutral beam injectors to be based on negative-ion technology.

Conceptual designs of tandem mirror reactors with thermal barriers use 150 to $400 \mathrm{KeV}$ neutral beams to reach central cell ignition. Pesent tandem mirror reactor designs are improving rapidly and indications are that mirrors have the potential to become attractive fusion reactors.

\section{Alternate Concepts}

The Office of Fusion Energy is persuing several plasma physics concepts as alternates to the tokamak and tandem mirror systems. The alternate concept neutral beam requirements are yet to be defined. As such, alternate concepts are not discussed in this neutral beam development plan. The neutral beam development activities discussed here provide the technology base for application to an alternate concept if needed.

\section{Reliabllity}

The neutral beam systems in use to date have been highly complex systems operating at the state-of-the-art. Whatever design margins that have existed have been fully exploited to provide the highest performance possible. As a result, it has generally taken a great deal of effort to find and correct initial installation problems and to keep the system operational. Operation at rated power has been difficult to obtain or to maintain. This has included a significant amount of hands-on maintenance of the equipment installed in the plasma device test cell: To datc, this has been cunsldered acceptable or at least tolerated and acknowledged as the status of the state-of-the-art and the difficulty of the experiment.

Because of the high power, long pulse, high energy density and ability to function in a radiation environment, and importance to the program of the large present and future generation of plasma experiments, it is necessary to improve the reliability of the installed neutral beam systems over that which has been obtained in the past. This need will be compounded by limitations of access to the test cell and limited contact maintenance therein imposed by the environment that results from $D-T$ operation and even intense $D-D$ operation.

The Military, Aerospace and Nuclear Industries provide equipment of high and proven reliability. This is done by: 
1. good design, with adequate design margin,

2. sufficlent testing to find and correct problems,

3. installed redundancy, and

4. operation limited to specified capabilities.

Areas 1,2 and 4 need increased emphasis. It is essential that adequate design margins be included and adhered to. Testing in the past has been mostly in the area of feasibility and performance demonstration. It is important that sufficient prototype operating time be allowed to find the various problems that exist and to demonstrate the acceptability of the fix prior to operation on the experiment. This will become increasingly important to facilities such as ETF where the expense of the device requires high availability and maintenance access is limlted by the radiation environment. Fina1ly, if rellable operation is to be retained, operation needs to he restricted to the agreed upon operating range.

E. Value Engineering and Cost Reduction

Value Engineering and Cost Reduction has always been a part of the overall neutral beam development program. The short-time scales allowed for spectfic projects have made it difficult to demonstrate substantial reductions on a given project, however, as the progression through various projects is reviewed, it is clear that reductions in per unit costs have been obtained. Economics of scale and more efficient utilization of system hardware results in cost reductions on a per unit basis. Note, however, that the larger systems are yet to be completed so that detailed cost comparisons may be premature.

It should be noted that about half of the costs are associated with the power supply subsystem. Further dramatic power supply cost reductions are unlikely except those associated with economics of increased size or numbers. W1th this in mind, it is apparent that cost reductions in this system will be obtalned by improvements in system simplification and overall efficiency. Improved efficiency not only reduces electrical system costs, but also reduces costs of energy removal systems such as fon dumps to. remove the energy wasted. This provides strong motivation for pursulng the direct energy recovery and negative ion programs.

F. Technology Transfer to Industry

In years past, neutral beam systems have been largely fabricated. in the national laboratories. This has been done because it is the most natural place to build advanced state-of-the-art systems, especially with the schedular pressure that has existed. As the size and complexity of the oyetems has grown, it has become desirable to contract with industry in areas when unique industrial expertise exists. Furthermore, the larger size is sufficient to elicit industrial interest. There has, therefore, been a natural trend 
of transferring the technology developed in the national laboratory system into industry such that. PDX, TFTR, MFTF, and Doublet-III components and systems are being manufactured in industry. This trend is expected to continue with industry taking a more active interest in and becoming more involved earlier in the design and development process.

Two industrial suppliers have fabricated TFTR sources. An important program element is to obtain industrial participation in the Advanced Positive Ion Source development. (See Section IV-B.) Unfortunately, such participation has been limited by the available funding.

III. Neutral Beam Technology -- State-of-the-Art

In this section the state-of-the-art developments needed to meet the heating requirements discussed previously are summarized. These are incorporated in the overall plan in section IV.

\section{A. Positive Ion Systems}

Key areas, where development effort is believed to be required, are given below.

Plasma Source. Imp rovements are needed in cathode lifetime and reliability, atomic ion fraction, gas and electrical efficiencies, pulse length, reduced impurities, and radiation hardening. Improved cathodes such as hollow cathodes and RF plasma generators need to be developed.

Accelerator Structure. Radiation hardened, long pulse accelerator structures for 40 to $150 \mathrm{KeV}$ operation require development. Techniques needed to be developed for conditioning electrodes in auxiliary discharges, thereby reducing conditioning times on experiments and major test facilities. New materials and designs for minimizing electrical breakdown problems will be considered:

Energy Recovery Elements. Direct recovery of the energy in the charged components of beams emerging from the neutralizer needs to be developed to make the system more efficient and to reduce the power loading on beam dumps and calorimeters.

Beam dumps and calorimeters. Reliable, actively-cooled high-power density beam dumps and calorimeters must be developed. Beam dump power-densities can be reduced by energy-recovery systems.

Diagnostics. Reliable diagnostics for fast non-interruptive analysis of the composition and optics of the neutral beams, and of performance and safety of the components and system must be developed on a continuing basis. 
Arc down energy. The TFTR, MFTF, and Doublet-III sources are sensitive to the total stored energy available to be dumped in a grid-to-grid arc. This places a limit of approximately 5 joules on the stored energy. As source yoltage, V, is increased, this stored energy increases as $v^{2}$. This 5 joule limitation needs to be investigated further because it leads to limits on source size and added power supply complexity. The PLT, PDX, and ISX sources appear to have a higher limit. There are differences in grid materials and differences in operating system methodology that may be contributing to this difference. This inconsistency needs to be resolved and if possible, the joule limit increased.

Power supplies and controls. Optimization of the neutral beam system to reduce the complexity and cost of power supplies and controls can make an important contribution. For example, it way le pussible to opcratc without high voltage regulation if the plasma source is properly controlled. Simplified protection systems are also being developed.

Vacuum system. Reduction (or elimination) of cryocondensation pumps operating at liquid helium temperature may be possible. Substitution of cryosorption or getter pumps may significantly improve operations. At a minimum more efficient utilization of the cryocondensation pumps needs to be explored. More efficient pumps, that operate at higher temperatures, as well as radiation hardened pumps, may need to be developed.

B. Negative Ion Systems

Negative ion sources have not received the same attention that has been directed toward positive ion sources. The feature that makes negative ion syscems actracllve, llamely the ease with which tho excess electron is removed, also complicates suurce develupiuent. Adding this excess electron efficiently in a manner where the ion can be efficiently accelerated has proven difficult in the environment of high power neutral beam systems.

An additional complicating tactor is chat the lleydllve iul has the same electrical charge as an electron, but is less mobile. Therefore, an effective means of accelerating negative ions to the desired high energies must be developed which does not also waste energy due to the undesirable acceleration of electrons. Those suurces which have achieved negative $10 \mathrm{n}$ buatus of $i^{100 \mathrm{ma} / \mathrm{cm}}$ at $10^{\prime} \mathrm{a}$ of $\mathrm{KeV}$ have experienced $\mathrm{I}_{\mathrm{e}} / \mathrm{I}_{i} \gtrsim 4$. An electron energy recovery system developed at ORFL has successfully recovered $96 \%$ of the electron energy at $20 \mathrm{kV}$ accel voltage. There are other sources under development which have limited operation at $\leqslant 1 \mathrm{KeV}$ and which have not reported large electron currents. Wheller these 
sources will maintain low electron currents due to some novel features at higher beam currents and energles remains to be seen.

The negative ion sources being studied in the U.S. are basically of two types: surface sources and double charge exchange sources. Surface sources are being studied at BNL, ORNL, and LBL. At BNL, variations of the magnetron and penning sources are being pursued. Until recently, compared to positive ion sources these sources have suffered from poor gas efficiency (1-2\%) and poor arc efficiency. The poor gas efficiency makes transporting and acceleration of the negative ions difficult because of the ease with which the excess electron is removed from the negative ion by a collision with a gas molecule. The poor electrical efficiency results in high arc power densities. The resulting high heat load has required that pulse lengths be kept short and total ion current limited. Where short pulses are desired and current requirements are modest, such as in large accelerators for high energy physics research, sources similar to the BNL negative ion source have proven to be a very reliable and effective. Any extension of the pulse length beygnd 0.1 second would require efficient heat removal at $\geq 1 \mathrm{Kw} / \mathrm{cm}^{2}$.

Recent semiplanatron work in the USSR at Novosibirsk has yielded significant ( $10 X)$ improvements in gas and arc efficiency. BNL is pursuing similar ideas, confirming a substantial improvement and hopes to produce a scaleable, long pulse source in late FY80.

The modified duoPIGatron being developed by ORNL is a novel idea applicable to any size positive ion source. A cesiated surface is immersed in the ion source plasma immediately above the extraction surface. Positive ions are accelerated into the surface, converted into negative ions, and then extracted. A weak transverse magnetic field is generated by current carrying conductors which is intended to retard any electron motion towards the extraction surface. Thus far, this source has shown little evidence of extracted electrons.

LBL is developing a surface converter source where a cesiated electrode is emersed in a low density plasma. Positive ions are accelerated into this converter surface by use of an appropriate electrical bias: The resultant negative ions are accelerated by this same bias, thus providing enough momentum to cross the cusp field confining the background plasma. This directed energy and the magnetic field may prove to be sufficient to reduce electron extraction and acceleration to an acceptable level. To date, $1.0 \mathrm{~A}$ of negative ions has been obtained in 10 second pulses. 


\section{$-12-$}

LBL and LLL have also been working on a double charge exchange source where a low energy positive ion beam is passed through a sodium or ceslum vapor and converted to negative ions by double electron capture. Cesium has a good conversion efficiency, but works best at low energies ( $1 \mathrm{KeV}$ ) where.it is difficult to make a high current density positive ton beam. Use of sodium and a higher energy positive ion beam has yielded 2.0 A of negative 1ons. While LLL believes this could be adapted to a mirror machine, all of the conceptual designs formulated to date have been large and unwieldly.

IV. Program Plan

A. Needs Suminary

The needs of the various projests dessrthed in the previous soctions have many features in common. In summary, the requirements are:

- long pulse (5 seconds to steady state) cooled grids long pulse plasma generator

- increased efficiency direct recovery or negative ions

- high atomic yield

- improved optics

- high reliability

- high energy

\section{B. Strategy}

\section{Positive Ion Systems}

To meet the positive Ion systems needs, an Advanced Positive Ion Source (APIS) is being developed by both ORNL and by LBL. The final APIS parameters are listed in Table IV-1. Not all of these features are required in the earlier versions of this source. Therefore, the final $\Lambda$ PIS parametera will be achieved lin stabes. Table IV-2 1ists basic APIS parameters as a function of the stage of development. These stages are keyed to meet various program needs and to capitalize on test stand and development capabilities as they exist. 
Table IV-1. Advanced Positive Ion System Parameters and

Desirable Features

- Long pulse capability 5 sec to steady state

- 75-100KeV/nucleon or $150-200 \mathrm{KeV}$ deuterium

- Up to 100 A per source.

- Energy recovery of full energy component

- High atomic yield - $\sim 90 \%$

-. High quality optics $\pm 0.7^{\circ}$ HWHM with' mintmum dispersive "tails"

- Source reliability $>95 \%$ for each source

- Consideration of close packing of sources for multiple source compact beam lines

- Source arc efficiency $\sim 1 \mathrm{~kW} / \mathrm{A}$ beam

- Gas efficiency - 50-75\%

- Reduce source conditioning time

- Increase source component lifetime.

Table IV-2. Stages of APIS. Development

$\begin{array}{lccc}\text { Stage } & \text { Pulse Length } & \text { Energy } & \text { User } \\ \text { I } & \sim 1.5 \mathrm{sec} & 120 \mathrm{KeV} & \text { TFTR-TFM } \\ \text { II } & \leq 5 \mathrm{sec} & 40-50 \mathrm{KeV} & \vdots \\ \text { III } & \leq 5 \mathrm{sec} & 80-120 \mathrm{KeV} & \text { PDX, ISX-C } \\ \text { IV } & 30 \mathrm{sec} & 50-100 \mathrm{KeV} & \because \text { ISX-C } \\ \text { V } & 30 \mathrm{sec} & 80-175 \mathrm{KeV}, & \text { MFTF-B, Zephyr } \\ \text { VI } & \text { continuous } & 150-175 \mathrm{KeV} & \text { NMS, ETF, INTOR }\end{array}$

2. Negative Ion Systems

Because the need for negative ion systems is not immediate; because of difficulties that have been experienced, and because of resource limitations, the development of negative Ion systems will be limited in the near term to demonstration of a proof of principle negative ion source. Once a successful proof of principle negative ion source is demonstrated or if program priorities dictate that more rapid development is: needed, efforts will be expanded to integrate the ion source with an accelerator and neutralizer system. The negative. ion source pronf of princtple goals are given, in Table IV-3.

Proof of principle work will be pursued at BNL, ORNL, and LBL as budgets permit. The budgets listed in this plan assume success in the next two years in the proof of principle work. 
Table IV-3. Negative Ion Source Proof of Principle Goals

Energy

Current

Pulse Length

Gas Efficiency and Optics
Low $(10-40 \mathrm{KeV}$ extaction potential only)

$10 \mathrm{~A}$ ions ( 5 A neutrals)

5 sec to steady state

As determined by system requirements

\section{Test Facilities}

Complex and sophisticated teot facilitico arc requirod for noutral beam development. The major development test facilities are listed in Table IV-4. In addition, there are a number of smaller test facilitico uced for various source component and subsys tem R\&D investigations. Approximately half of the costs associated with neutral beam development are associated directly with the costs of building, upgrading and operating these large test facilities. Becduse of the large throughput of energy in the large test factlities, the fraction of the budget required for test facilities will increase in the future. Development of sources for upgrades of existing experiments can be accomplished on upgrades of these existing test facilities.

The test facilities as they now exist are not adequate to test the APIS. They are adequate to test scale test vehicles for development of grid cooling, cathodes, etc. To be able to test the full size versions two upgrades will be undertaken.

1. LBL

The TFTR prototype beam line at LBL (NBSTF) will be upgraded to the parameters shown on Table IV-4. This will include replacing the bending magnet and ion dump system and calorimeters with long pulse versions, upgrading the power supply and control/data systems for long pulse and increasing the shield thickness somewhat. The upgraded facility will be named the Neutral Beam Engineering Test Facility (NBETF).

The NBETF will be a national facility capable of testing ORNL, LLL, and LBL sources. Access for test time will be scheduled in much the same way as experimental time is scheduled on large high energy physics accelerators. Management will be separate from the LBL neutral beam R\&D management. 
Table IV-4. Neutral Beam Development Test Facility Capabilities

Facility

Present Capability

Upgraded Capability

Comments

Oak Ridge National Laboratory

Medium Energy Systems Test Facility (MESTF)

High Power Test Facility (HPTF)

Lawrence Berkeley Laboratory

Test Stand III- $\dot{A}$ (TSIIIA)

Test Stand III-B (TSIIIB)

Neutral Beam Systems Test

Facility/Neutral Beam

Engineering Test

Facility (NBSTF/NBETF)

Lawrence Livermore Laboratory

High Voltage Test Ständ (HVTS)
$150 \mathrm{KeV}, 15 \mathrm{amp}, 5 \mathrm{sec}$.

$150 \mathrm{KeV}, 15 \mathrm{~A}, 30 \mathrm{sec}$.

$150 \mathrm{KeV}, 80 \mathrm{~A}, 50 \mathrm{msec}$.

40-60ReV, $100 \mathrm{amp}, 1 / 2 \mathrm{sec}$

$15 \mathrm{GKeV}, 50 \mathrm{amp}, 1 / 2 \mathrm{sec}$.

$150 \mathrm{KeV}, 65 \mathrm{~A}, 10 \mathrm{sec}$. ( 9.75 megawatts)

120KeV, $65 \mathrm{~A}, 1.5 \mathrm{sec}$.

$175 \mathrm{Kev}, 65 \mathrm{~A}, 30 \mathrm{sec}$. $120 \mathrm{KeV}, 80 \mathrm{~A}, 30 \mathrm{sec}$, $10 \%$ duty cycle
No shielding

No shlelding
$120 \mathrm{KeV}, 65 \mathrm{~A}, 1.5 \mathrm{sec}$. $8 \mathrm{JjeV}, 80 \mathrm{~A}, 0.5 \mathrm{sec}$.
Limited shielding

May be used for negative ion acceleration later

Shielded. New name (NBETF) applies

to upgraded facility This facility will be the major national R\&D facility for the intermediate. future

To be used for MFTF \& Doublet-III project 
2. ORNL

The HPTF at ORNL will be upgraded by increasing the pumping and upgrading calorimeters and power systems to support APIS testing in Hydrogen. $\therefore$

The HVTS has been turned over to the MFTF project to be used to support active confinement experiments. This will relieve pressure for confinement experiment production source testing that has conflicted with $R \& D$ test time needs. This facility will be upgraded by addition of an MFTF power supply and probably by addition of a long pulse calorimeter. Since it is dedicated to direct user support rather than source/system development, it is beyond the scope of this plan.

Development of the neutral beam system for specific experiments has included development and operation of a prototypé neueral beam systein. ETF will require such a prototype. The capability to further upgrade the LBL NBSTF to meet this need is being investigated. It is doubtful if the full needs of the ETF project can be met without a major rebuilding of the facility, in which case it may be more cost effective. to build an entirely new fac1lity. ORNL has proposed such a facility.

D. Detail Program Plan

\section{Positive Ion Systems}

The program for development of positive Ion neutral beam systems is shown in Figure IV-1 and Figure IV-2.

For upgrades" of existing experiments, the neutral beam system that is already in existence will be upgraded to accommodate the advanced source. In these applications, the thrust of the development program is to provide the advanced source and to assist as needed in the upgrade of the remainder of the system.

The development program will develop R\&D prototype sources for particular experiments. Ihe user has traditionally been and will continue to be responsible for the prototype and production system. The development program will be available to assist the nser when needed. The budgets shown are, therefore, for generic source development only. Fabrication of project specific R\&D sources must be funded incrementally when that project is approved. 
FIGURE IV-1. LBL POSITIVE ION BASED NEUTRAL BEAM DEVELOPMENT

\begin{tabular}{|l|l|l|l|l|l|l|}
\hline \multicolumn{1}{|c|}{ FY } & 80 & 81 & 82 & 83 & 84 & 85 \\
\hline $\begin{array}{l}\text { SOURCES } \\
\text { SCALE SOURCE } \\
\text { OPERATE 120 KV, 1.5 sec } \\
\text { OPERATE 120/150 KV 5-10 sec } \\
\text { OPERATE 120/150 KV 30 sec }\end{array}$ & & & & & & \\
FULL SIZE SOURCE \\
FABRICATE 1st MODEL \\
OPERATE 120 KV, $20 \mathrm{~ms}$ \\
OPERATE 120 KV, 1.5 sec \\
OPERATE 80 KV, 20 msec \\
OPERATE 80 \& 120 KV, 5 sec \\
OPERATE 80 KV, 30 sec \\
OPERATE 150 KV, 20-30 s \\
TEST FACILITIES
\end{tabular}

FIGURE IV-2. ORNL POSITIVE ION BASED NEUTRAL BEAM DEVELOPMENT

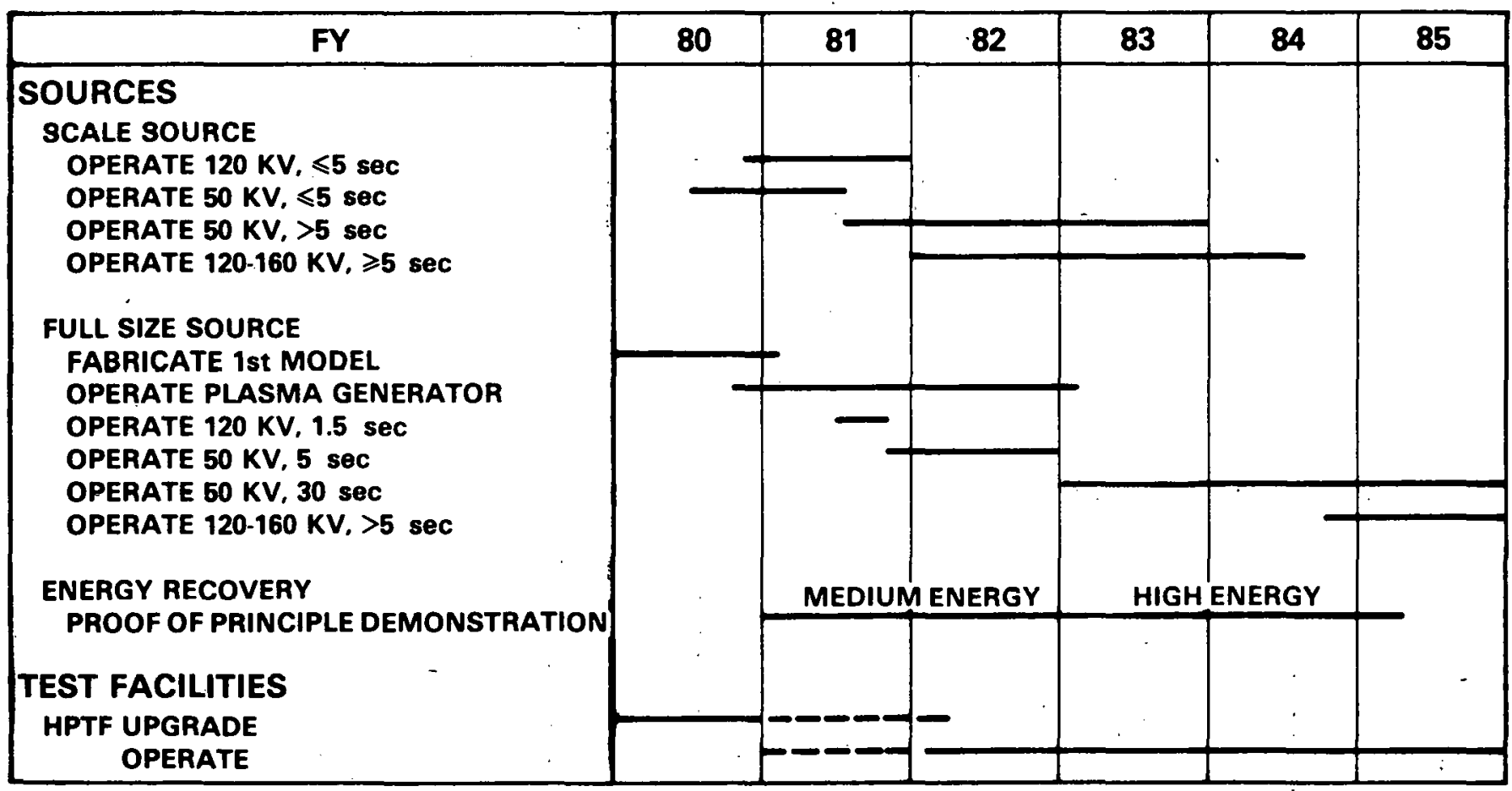


FGURE IV-3. NEGATIVE IDN NEUTRAL BEAM PROGRAM DUTLINE

\begin{tabular}{|c|c|c|c|c|c|c|c|c|c|c|c|}
\hline FISCAL YEARS & 80 & 81 & 82 & 83 & 84 & 85 & 86 & 87 & 88 & 89 & 90 \\
\hline $\begin{array}{l}1 \text { AMPERE SOURCE } \\
\text { DEVELOPMENT }\end{array}$ & & \multicolumn{2}{|c|}{$\begin{array}{l}\text { CONCEPT* } \\
\text { SELECTION }\end{array}$} & & & & & & & & \\
\hline \multicolumn{12}{|l|}{ OANL } \\
\hline BNL & & & & & & & & & & & \\
\hline $\begin{array}{l}10 \text { AMPERE } \\
\text { PROOF OF } \\
\text { PRINCIPLE }\end{array}$ & & & & & & & & & $\cdot$ & & \\
\hline $\begin{array}{l}200 \mathrm{KeV} \text {. TEST } \\
\text { MFTF-B PROTOTYPE }\end{array}$ & & & & & & & & & . & & \\
\hline $\begin{array}{l}\text { MFTF-B APPLICATION } \\
\text { (\& OTHER APPLICATIONS) }\end{array}$ & & & & & & & & & & & \\
\hline
\end{tabular}


The heart of any neutral beam system is the source subsystem. It is the technologically most complex and is the area with the most uncertainty. Included in the development is the interfacing and development of electrical equipment required for source operation. Therefore, the early stages of system development concentrate on the source subsystem that meets user needs. The final source and system parameters result from a closely coupled iterative development and design activity. This culminates in an operating system, the first unit of which is usually a "prototype" which is thoroughly tested and used to identify and solve problems. The solutions to these problems are then fed back into the design, fabrication, installation and operating sequence of the "production" units. Because of the need to find and correct problems in the prototype system before production hardware gets too far along, early start of prototype work is desired.

The needs of the program are sufficiently aggressive and diverse to justify the involvement of two competing laboratories, ORNL and LBL. These two laboratories have historically competed for the users attention on many projects. This competition has resulted in certain applications upon which each laboratory has concentrated.' It is natural to assign work on upgrading these neutral beam systems to the same laboratories. In new areas such as Zephyr and ETF where the technology and conceptual design of the system are just now being considered, it is appropriate that the competition be maintained at least until the technology problems and their solutions come more clearly into focus. Responsibility assignments are made in Table IV-4. Note that this is an extension to Table IV-2.

\begin{tabular}{|c|c|c|c|c|}
\hline Stage & Pulse Length & Energy & User & $\begin{array}{l}\text { Development } \\
\text { Laboratory }\end{array}$ \\
\hline I & $\leq .1 .5 \mathrm{sec}$ & $120 \mathrm{KeV}$ & TFTR-TFM & ORNL \& LBL \\
\hline II & $\leq 5 \mathrm{sec}$ & $40-50 \mathrm{KeV}$ & PDX, ISX-C & ORNL \\
\hline III & $\leq 5 \mathrm{sec}$ & $80-120 \mathrm{KeV}$ & D-III, TFTR-U & LBL \\
\hline IV & $30 \mathrm{sec}$ & $50 \mathrm{KeV}$ & ISX-C & ORNL \\
\hline V & $30 \mathrm{sec}$ & $80 \mathrm{KeV}$ & MFTF-B & T.BT. \\
\hline VI & continuous & $150-175 \mathrm{KeV}$ & $\begin{array}{c}\text { Zephyr, MNS, } \\
\text { ETF, INTOR }\end{array}$ & ORNL \& LBL \\
\hline
\end{tabular}


Note also the assignment of a TFTR-TFM source to both laboratorles. This assignment was made about two years ago before the other needs came more clearly into focus. Because of the prominant position TFTR plays in the program and because of the amount of work already accomplished, no change is made in that assignment at this time.

2. Negative Ion Systems

The negative ion neutral beam development program has proceeded at a modest pace. The program has suffered from low priority and lack of specific user requirements. The proof of principle goal of Table IV-3 was established about $11 / 2$ years ago to provide focus for the work. The program has been working toward this goal. During a program review on April 2 and 3,1980 , the review panel concluded that no source concept satisfies the proof of principle goal at the present time. Each laboratory is presently working with sources that produce or are expected to produce about 1 ampere of negative ions. From the results to date, it is not clear which source is most likely to meet the proof of principle goal.

The panel recommended that BNL, LBL, and ORNL proceed with their 1 ampere source development through the remainder of FY80 and FY81. The emphasis would be placed not only on parametr1c performance of the source, but also in obtaining a better understanding of how the source operates. The goal for this period of time is:

$\begin{array}{ll}\text { Energy: } & \leq 40 \mathrm{KeV} \text { (extraction potential only) } \\ \text { Current: } & >1 \mathrm{~A} \\ \text { Pulse Length: } & 5 \text { seconds to steady state }\end{array}$

The panel also recommended that in parallel with the 1A demonstration, each lab undertake a neutral beam system study illustrating how their particular source concept would be applied to a $10 \mathrm{~A} \mathrm{D}\left(\mathrm{H}^{-}\right), 200 \mathrm{KeV}$ neutral injector. The system study would be used to help guide the experimental program by pointing out areas where the source concept needs improvement and areas where better measurements are needed. The completed system study should be consistent with either achieved source parameters or experimentally-based extrapolation of achieved source parameters; particularly in the critical system areas of gas efficiency, optics/emittance, stacking, power efficiency/cooling; current density, and accelerated electrons. The completed study will aid in evaluation of the source concept by illustrating system design trade-offs required to compensate for source concept weaknesses, and conversely, by illustrating system advantages due to source concept strengths. 
The final product of this system study will be a conceptual design of a 10 ampere, $200 \mathrm{KeV}$ system and a.proposal to proceed with the 10 ampere proof of principle, followed by building the entire system if warranted by the results.

By following the above course of action, namely, completion of 1 ampere development work and a conceptual design of a 10 ampere, $200 \mathrm{KeV}$ system, a foundation will be available upon which to select the concept to be carried through 10 ampere proof of principle and application to a $200 \mathrm{KeV}$ system. A review will be scheduled to make this selection in approximately late FY81, so that the 10 ampere work can proceed in FY82.

E. Budgets

A major consideration in preparing a plan is the projected budget levels. This plan paces the development to. fit within the projected budget levels. Projected budgets are listed in Table IV-5.

An important point is that the longer pulse length neutral beams required in the future (see Figure 1) will be more expensive to develop because they are beyond the state-of-the-art of short pulse technology now employed. These systems will be required as a minimum to handle 40-50 times the energy presently injected. Long pulse operation will require application of new technologies within the source structure and the other components of the system. For example, the limitations on the ability to dissipate waste power on thick, thermal inertia targets has already been seen in the PDX development where baffles, ion dumps, and calorimeters have been melted. Active cooling will be required in many places in the neutral beam source and in the entire system.

The test facilities that exist today are simply not capable of operating even several second pulse length full size sources, much less steady state sources. The upgrades to the HPTF and. ND3TF are required for this development to proceed. This implies the need for a considerable increase in. funding. The budgets shown are intended to provide for this.

The budgets shown in Table IV-5 is. for the generic technology development and does not include funds for developing the... specific sources for projects shown in Tables II-1 and. II-2. It is assumed that as project requirements,are agreed upon and activities put in place to develop the neutral beam system or system upgrade, that this activity will include funding for developing the $R \& D$ prototype source for that project. 
Table IV-5. Neutral Beam Development Operating. Budgets (Proposed)

(FY81 constant dollars used for FY82-85)

Congressional Need

Fiscal Year $80 *$ 81

81

82

83

84

85

Positive Ion

Development

Base Program

Source R\&D

$$
3,500 \quad 3,250
$$

4,400

4,400

4,400

4,400

4,400

Test Facility

Upgrades and

Operations

$4,000 \quad 1,900$

$\underline{6,5 n !}$

$5,0 \cap 0$

$\underline{5,000}$

$5,000 \cdot 5,000$

TOTAL POSITIVE ION.

DEVELOPMENT

$\begin{array}{lllllll}7,500 & 8,150 & 10,900 & 9,400 & 9,400 & 9,400 & 9,400\end{array}$

Negative Ion

Development

Base Program-Proof

of Principle $\quad 1,500$

$1,500 \quad 1,700$

2,000

2,000

2,000

2,000

Prototype System

Tests

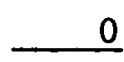

0

0

0

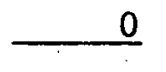

$\underline{500 \quad 1,000 \quad 1,000}$

TOTAL NEGATIVE ION

DEVELOPMENT

$$
1,500
$$

1,500

1,700

2,000

$2,500 \quad 2,500$

2,500

'IU'I'AL NEUTRAL

BEAM DEVELOPMENT 9,000

$9,600 \quad 12,600$

11,400

$11,90011,900$

11,900 
Appendix A - Definition of Terms

1. A positive ion beam line system is one which produces energetic neutral particles through the production, accleration and neutralization of positively charged particles.

2. A negative ion beam line system is one which produces energetic neutral particles through the production, acceleration and neutralization of negatively charged particles.

3. A complete beam line system, positive or negative, is composed of an ion source, positive or negative, an accelerating column, ion to neutral conversion cell (neutralization cell), charged-particle deflection magnet and beam dumps and/or a direct recovery unit, calorimeter, cryopump, drift duct, diagnostics, and associated electrical equipment controls.

4. A positive ion source is a source of positive ions produced by lonizing or stripping an electron from a source of gas atoms or molecules, e.g., $\mathrm{H}$ or D.

5. A negative ion source is a source of negative lons produced from a source of gas atoms and positive lons, e.g., $\mathrm{H}$ or $\mathrm{D}$, by the addition of electrons.

6. Direct extraction 1s a term describing the production of negative Ions in a single stage plasma generator.

7. Double charge exchange is a term describing the production of negative ions in a two stage process: creation of low energy positive ions (first process) which are then converted to negative ions (second process).

8. Plasma generator is that portion of an ion source in which the input gas is ionized into a plasma of ions and electrons.

9. Species is an abbreviated term referring to the ratio of atomic to diatomic to triatomic ions created in the ion source plasma generator.

10. The source power efficiency is a term describing the electrical efficiency for producing ions in an ion source and is equal to the ratio of the source arc and $f$ ilament power in kilowatts to the extracted ion current in amperes.

11. The gas efficiency is a term describing the efficiency of gas utilization in producing lons in an ion source and is equal to the number of nucleons extracted at high energy divided by the number of nucleons put in.

12. The arc supply is a source of electrical energy which is utilized in the production of lons in an ion source. 
13. The filament or cathode of an ion source is a source of electrons whose energy is provided by the arc supply in order to lonize the gas for ion production.

14. The filament supply is a source of electrical energy which heats the filament to electron emitting temperature.

15. The accelerating column of an fon source or beam line system is a carefully aligned assembly of electrodes which.electrically accelerate and focus the ions in the desired direction.

16. The high voltage power supply, also known as the accel supply is the source of electrical energy which accelerates the ions to the desired terminal energy.

17. The power supply known as the decel supply is the source of electrical energy which inhibits electrons traveling from the ion beam drift region back through the accelerator column to the ion source.

18. An accel-decel system is an abbreviated name-for an accelerator column consisting of one or more accelerator sections or electrodes for accelerating ions and one section for inhibiting electron flow in the direction reverse to the ions. :

19. Backstreaming or backstreaming electrons is a term used to describe that class of electrons: which traverse a positive ion accelerator column in the reverse direction.

20. The neutralization cell or charge exchange cell is that section of a beam ine immediately folloiwing the accelerator column which contains gas (usually the same as that from which the beam is produced) through which the energetic ions: travel and recelve an electron from cold gas molecules.

21. The efficiency of neutralization is the fraction of energetic Ions that are converted to: energetic neutrals in the neutralization or charge exchange cell.

22. Charge exchange is the term used to describe the transfer of an electron trom one particlé tó anocher, from a cold gas molecule lu all energetic Ion in a neutralization cell.

23. An equilibrium cell is a charge exchange or neutralization cell which has sufficient gas to assure the maximum percentage of charge exchange of atomic ions within the cell.

24. Full energy neutral particles are those particles that are created from . full energy atomic ions by charge exchange in the neutralization cell. 
25. Half energy neutral particles are those particles that are created by charge exchange between the cold gas in the neutralization cell and dissociated full energy diatomic lons in the ion beam.

26. Third energy neutral, particles are those particles that are created by charge exchange between the cold gas in the neutralization cell and the dissociated full energy triatomic ions in the ion beam.

27. The deflection or bending magnet is a device for creating a magnetic field which deflects the unneutralized portion of the beam emerging from the neutralization cell in a desired direction away from that being taken by the neutral beam.

28. Beam dump. The water cooled plates on which the unneutralized full energy, half energy and third energy ions terminate after traversing the deflection magnet.

29. Energy recovery. The method by which the energy of the unneutralized full energy tons is recovered electrically rather than being lost as thermal energy on the beam dump.

30. Cryopump. A pump which effectively pumps by condensing the $H$ or $D$ gas flowing from the ion source and/or gas neutralization cell on a liquidhelium-cooled-metal surface.

31. A calorimeter is a device by which the energy or power of an impinging ion or neutral beam may be measured.

32. Defining plates are a system of water-cooled plates which serve to define the shape of a beam by removing the stray particles on the outer edge.

33. The drift duct is a high-vacuum channel through which a neutral beam is transported into the desired target fusion plasma.

34. A Gaussian profile is a term used to describe a bell-shaped neutral beam radial intensity distribution. 
Appendix B - Giossary of Abbreviations

Doublet-III - A tokamak at General Atomic

ETF - Engineering Test Facility

GA - General Atomic Company

ISX - Impurity Studies Experiment; a tokamak at ORNL

INTOR - International Tokamak Reactor

LBL - Lawrence Berkeley Laboratory

LLL - Lawrence Livermore Laboratory

MFTF - Mirror Fusion Test Facility - LLL

MFTF-B - Án upgrade of MFTF to be a tandem mirror test facility - LLL

ORNL - Oak Ridge Nationa1 Laboratory

PDX - Polodial Diverter Experiment; a tokamak at PPPL

PLT - Princeton Large Torus; a tokamak at PPPL

PPPL - Princeton Plasma Physics Laboratory

TMX - Tandem Mirror Experiment - LLL

TFM - Tokamak Flexability Modification; an upgrade of TFTR-PPPL

TFTR - Tokamak Fusion Test Reactor at PPPL

2XIIB - A mirror experimental device at LLL

Zephyr - A: proposed' high field tokamak ignition experiment at Garching, Germany. 